\begin{tabular}{l}
\hline A INTENÇÃO DO PROFESSOR E A PERCEPÇÃO DO ALUNO QUANTO À \\
EXPLICITAÇÃO DE OBJETIVOS EM AULAS DE L2 \\
\hline Rosane Rocha PESSOA**
\end{tabular}

RESUMO

A constatação, cada vez mais freqüente, da grande divergência entre a intenção do professor e a percepção do aluno tem levado pesquisadores de sala de aula à conclusão de que o propósito pedagógico de uma aula deve ser informado ao aluno, posição esta que se confirma nos livros de metodologia de ensino de inglês. Mas será que a apresentação de objetivos diminui a lacuna entre a intenção do professor e a interpretação dos alunos? Este estudo compara as percepções de uma professora e três alunos com relação a duas aulas, uma em que não houve a explicitação de objetivos e outra em que os objetivos foram apresentados aos alunos.

Palavras-Chave: Explicitação de objetivos, intenção do professor, percepção do aluno.

\title{
INTRODUÇÃO
}

Pesquisas recentes sobre a sala de aula têm demonstrado que as intenções do professor são dificilmente percebidas pelos alunos (BREEN, 1987; Kumaravadivelu, 1991; Block, 1994; Nunan, 1996; Block, 1996), e tal constatação tem levado alguns destes pesquisadores à conclusão de que o professor deve explicitar os objetivos das aulas para os alunos. Também nos livros de metodologia de ensino de inglês, os autores parecem concordar que a apresentação dos objetivos de cada aula para os alunos é um imperativo pedagógico básico (WILlis, 1981, Doff, 1988,

* Trabalho apresentado como comunicação no III Seminário de Línguas Estrangeiras da Universidade Federal de Goiás (UFG), Goiânia, outubro de 1999.

** Professora assistente de Língua Inglesa da Faculdade de Letras da UFG, mestre em Literatura Brasileira pela UFG e doutoranda em Letras: Estudos Lingüísticos, na Universidade Federal de Minas Gerais (UFMG). 
Medgyes \& Malderez,1996). No entanto, minha experiência como supervisora do Centro de Línguas da Universidade Federal de Goiás, por dois anos, e como professora de cursos de formação e de formação continuada de professores mostra que os professores, em geral, não apresentam objetivos. Muitos deles alegam razões para não fazê-lo, o que pôde ser constatado em uma entrevista feita com professores com quem tive contato enquanto realizava este estudo. As alegações mais comuns são: não interessa ao aluno, destrói o elemento surpresa da aula, impede que o plano de aula possa ser alterado durante sua execução e faz que os alunos se remetam a experiências de aprendizagem anteriores que podem interferir de forma negativa na apreensão do conteúdo.

Em Lingüística Aplicada, não é nova a idéia de que os alunos percebem as aulas de forma bastante diferente da aula concebida pelo professor. Dakin (1973, p. 16) já dizia que “embora o professor tenha o controle das experiências a que o aluno está exposto, é o aluno que seleciona o que vai aprender". ${ }^{1}$ Breen (1987) também argumenta que os alunos são capazes de interpretar erroneamente mesmo as atividades mais bem preparadas e utilizadas. Além disso, a forma como os aprendizes percebem as aulas depende muito de seu sistema de crenças, que, segundo Richards e Lockhart (1996), fundamenta-se nas concepções da língua, dos falantes da língua, de ensino, de aprendizagem de língua, de comportamento adequado em sala de aula, de si mesmos e de seus objetivos.

Talvez tenha sido por causa dessa autonomia do pensamento do aprendiz que se consolidou a idéia de que os objetivos devam ser explicitados, a fim de que se possa estreitar a lacuna entre as intenções do professor e as percepções dos alunos. Mas será que a apresentação dos objetivos acarretaria alguma mudança nesse quadro?

A idéia desta investigação nasce, então, da contradição que existe entre o que os teóricos afirmam (a importância de se evidenciarem os objetivos pedagógicos das aulas) e o que é normalmente feito em sala de aula (a ausência dessa explicitação). Interessa-nos, portanto, examinar se a apresentação dos objetivos faz que haja uma maior convergência entre as intenções do professor e as percepções dos alunos. Assim, o problema que se coloca é: como professores e alunos interpretam uma aula em que os objetivos são explicitados e outra em que não o são? 
Mais recentemente, a pedagogia de L2 tem se afastado cada vez mais da visão técnica de ensino, voltada para o treinamento de professores, e tem desenvolvido uma abordagem mais holística, que se fundamenta na noção do professor como um pensador reflexivo e crítico (Richards, 1998). Assim, grande ênfase tem sido dada às interpretações que professores e alunos fazem de objetivos e eventos de aulas, gerando mais questionamentos em torno da questão. Com essa investigação, esperamos contribuir para as discussões sobre a importância de o professor explicitar objetivos para o aluno, em aulas cujo foco é a habilidade oral.

\section{REVISÃO DE LITERATURA}

Um dos propósitos dos livros de metodologia de ensino de língua inglesa é fazer que os professores planejem e organizem as aulas, além de possibilitar que os alunos tirem o máximo proveito da aprendizagem e da interação com seus pares. Nas sessões sobre planejamento, há, em geral, referências sobre a explicitação dos objetivos, normalmente recomendada pelos autores.

O primeiro objetivo de um capítulo sobre estágios de uma aula, segundo Willis (1981, p. 32), é "fazer que os professores introduzam e definam os objetivos de cada estágio da aula para o benefício dos alunos”. A autora não apenas propõe que se discuta a importância de tornar os alunos conscientes dos objetivos, mas também sugere como isso pode ser feito e fornece exemplos. Doff (1988) também ressalta a importância de introduzir cada estágio da aula e de promover a discussão através de exemplos.

Medgyes \& Malderez (1996, p. 32), em uma seção intitulada “Explicitação de objetivos”, cita Nunan (1994), quando diz que “um passo crucial para se criarem aprendizes autônomos e motivados é explicitar os objetivos de uma atividade”. Os dois autores ainda acrescentam que devemos definir a autonomia do aluno como o avanço para uma melhor compreensão do que é língua e aprendizagem, a fim de que possam assumir um papel mais autônomo no que diz respeito à própria aprendizagem.

A despeito das recomendações dos autores de cursos de formação de professores, as pesquisas confirmam a minha experiência de que 
muito poucas aulas observadas começam com a apresentação de objetivos (Nunan, 1996; Block, 1996). Block (1996) investiga as similaridades e diferenças nos relatos que professores e alunos fazem dos eventos de sala de aula e chega à conclusão de que "a análise do propósito pedagógico não é de domínio exclusivo dos professores” e de que os alunos estão sempre buscando entender o sentido das aulas. Daí a necessidade de fazer que "as atividades em sala de aula pareçam sensatas e coerentes para os alunos” (p. 192).

Richards \& Lockhart (1996) afirmam que professores definem os objetivos de duas formas: objetivos gerais (macro-plans) ou objetivos específicos (micro-plans). Além disso, eles normalmente não planejam suas aulas em torno de objetivos comportamentais (que descreve o que se pretende que o aluno aprenda), mas sim em função do que o professor faz (instructional goals); ou da seqüência de atividades ou tópicos (descriptions of course and language content); ou da quantidade de conteúdo a ser dado (quantity of learning content); ou, finalmente, dos materiais a serem utilizados (learning materials) (BRINDLEY, 1984).

Nunan (1988, p. 61) afirma que a explicitação de objetivos comportamentais possibilita que

- os alunos venham a ter uma idéia mais realista do que vai ser alcançado em um curso;

- a aprendizagem passe a ser vista como uma expansão gradual de objetivos atingíveis;

- os alunos se mostrem mais sensíveis ao papel de aprendizes para que, assim, suas vagas concepções do que é ser um aluno se tornem mais precisas;

- o aluno seja capaz de se auto-avaliar;

- os alunos possam perceber a relação entre as atividades em sala e suas necessidades reais;

- o desenvolvimento das habilidades possa ser percebido como gradual e não como um processo sem sentido.

Também em outras áreas do conhecimento e em esferas mais amplas que a da sala de aula, vozes se ouvem nesse sentido. Segundo Gardner (1995, p. 16):

Uma das suposições nas quais se baseia o planejamento da escola ideal do futuro é a de que, atualmente, ninguém pode saber tudo 
o que há para ser aprendido, de modo que a escolha é inevitável, e uma das coisas que gostaria de defender é que as escolhas que fazemos para nós mesmos, e para as pessoas que estão sob nossa responsabilidade, deveriam pelo menos ser escolhas informadas.

Segundo Breen (1987, p. 26), na ausência da apresentação de objetivos, os alunos adotam o que ele chama de orientação de sobrevivência, ou seja, apóiam-se em critérios externos, como o de fazer as atividades porque a professora pediu, sem se sentirem envolvidos no processo. Assim, para que os alunos adotem uma orientação de realização, que implica perceber a necessidade de participarem das atividades, eles devem, em algum momento, se conscientizar da importância delas. Para isso, o professor deve tornar claros os objetivos de tudo o que é feito em sala.

No entanto, apesar de os autores concordarem com a explicitação dos objetivos, não parece haver pesquisas que comparem aulas em que estes são apresentados com aulas em que são omitidos. Block (1996) e Nunan (1996) chegam a esta conclusão ao constatarem a grande divergência entre as intenções do professor e as interpretações dos alunos. Kumaravadivelu (1991, p. 98), num estudo preliminar, identifica dez fontes desta discrepância: cognitiva, comunicativa, lingüística, estratégica, cultural, procedimental, de avaliação, de atitude, de instrução e pedagógica. A divergência pedagógica ocorre quando os alunos interpretam de forma diferente os objetivos do professor. Em um trecho transcrito pelo autor, é evidente que a percepção de dois alunos difere e nenhuma das duas interpretações coincide com a intenção da professora.

Esta questão pedagógica foi, portanto, o objeto de nossa pesquisa, que passaremos agora a relatar.

\section{Metodologia}

O estudo que me propus a fazer foi investigar as percepções de um professor e de três alunos no tocante a duas aulas: uma em que o professor não apresenta os objetivos para os alunos, e outra em que os objetivos da aula e/ou das atividades realizadas em sala são verbalizados. As aulas em questão foram ministradas em um ambiente natural de aprendizagem, ou seja, não foram constituídas para o fim dessa inves- 
tigação. A única interferência do pesquisador se deu no sentido de garantir que a segunda aula fosse introduzida pela apresentação dos objetivos e que, ao final das atividades, a professora perguntasse aos alunos o porquê de terem sido realizadas.

As duas aulas foram observadas no Centro de Línguas da Universidade Federal de Goiás e contou com a participação de uma professora $(\mathrm{P}),{ }^{2}$ interessada em pesquisas em sala de aula, e de duas alunas (A1 e A2) e um aluno (A3), que se ofereceram como voluntários, no início da primeira aula, quando foi dito que os estudantes entrevistados deveriam fornecer sua impressão tanto sobre aquela aula quanto sobre a seguinte.

Os cursos de inglês do Centro de Línguas são semestrais, os livros utilizados são da série Interchange e o foco das aulas são as atividades de compreensão e produção orais. Vale destacar que as atividades de compreensão e produção escritas são geralmente desenvolvidas fora da sala de aula. As aulas observadas para esse estudo foram de nível iniciante, e a observação aconteceu na segunda semana do segundo semestre de 1999, ou seja, quando os conteúdos do curso estavam começando a ser apresentados. Cada aula teve a duração de uma hora e quarenta minutos.

Os dados foram coletados em duas fases: 1) durante as aulas, com observação e anotação dos passos da aula; 2) imediatamente após as aulas, quando a professora e os alunos foram entrevistados a respeito dos objetivos dessas aulas. As entrevistas foram feitas em língua materna, gravadas em fita cassete e, mais tarde, transcritas para análise.

Antes da primeira aula, a professora e os alunos foram informados apenas de que seria um estudo das interpretações que eles faziam dos eventos de sala de aula. E, no final desta aula, foram feitas as seguintes perguntas:

\begin{tabular}{|c|c|}
\hline ENTREVISTA COM A PROFESSORA & ENTREVISTA COM OS ALUNOS \\
\hline $\begin{array}{l}\text { 1. O que você queria que os seus alunos } \\
\text { aprendessem nessa aula? } \\
\text { 2. Você acha que atingiu esses objetivos? } \\
\text { Como você sabe? } \\
\text { 3. Você disse aos alunos o que você } \\
\text { queria que eles aprendessem? Por quê? }\end{array}$ & $\begin{array}{l}\text { 1. O que você aprendeu hoje? } \\
\text { 2. Que atividades foram feitas em sala? } \\
\text { 3. O que você fez nessas atividades? } \\
\text { 4. O professor o ajudou na realização } \\
\text { dessas atividades? }\end{array}$ \\
\hline
\end{tabular}


Após a entrevista com a professora, ela foi informada do propósito específico da pesquisa e da necessidade de incluir, na aula seguinte, a apresentação dos objetivos que ela esperava atingir, além da argüição a respeito de como a aula foi percebida pelos alunos.

Ao final da segunda aula, os informantes responderam às seguintes perguntas:

\begin{tabular}{|c|c|}
\hline ENTREVISTA COM A PROFESSORA & ENTREVISTA COM OS ALUNOS \\
\hline $\begin{array}{l}\text { 1. O que você achou da experiência de } \\
\text { dizer para os alunos o que você } \\
\text { esperava que eles aprendessem nessa } \\
\text { aula? } \\
\text { 2. Os alunos reagiram à aula de forma } \\
\text { diferente? }\end{array}$ & $\begin{array}{l}\text { 1. O que você aprendeu hoje? } \\
\text { 2. Que atividades foram feitas em sala? } \\
\text { 3. O que você fez nessas atividades? } \\
\text { 4. O professor o ajudou na realização } \\
\text { dessas atividades? }\end{array}$ \\
\hline
\end{tabular}

Estudos sobre a percepção dos informantes, em geral, obtêm dados por meio de relatos escritos, tais como diários e questionários (BREEN, 1987; Slimani, 1987, citado por Block, 1996; Bailey, 1996; Richards \& Ho, 1998), ou por relatos orais, tais como entrevistas (BLOCK, 1996; NunAN, 1996). Escolhi a entrevista, com questões abertas para direcionamento do foco, porque, assim, seria possível esclarecer dúvidas com relação às perguntas e às respostas, já que não contava com outra oportunidade de fazê-lo.

A análise dos dados ocorreu em dois momentos: primeiramente, com uma quantificação dos dados para a obtenção de um quadro geral, e, em seguida, com uma análise qualitativa, destacando aspectos relevantes dos dados. A análise não contou com a colaboração dos participantes da pesquisa.

\section{RESULTADOS}

Primeiramente, os resultados serão apresentados, o número de objetivos descritos pela professora e mencionados pelos alunos será comparado, para depois fazermos uma análise mais detalhada.

Os quadros 2 e 3 mostram se os objetivos pretendidos pela professora (Quadro 1) foram, pelo menos, mencionados pelos alunos, em toda a entrevista. Os objetivos descritos na primeira aula foram obtidos não 
apenas por meio da entrevista, mas também do plano de aula e, depois, confirmados por P. Já os da segunda, foram citados da forma como foram apresentados para os alunos.

QuAdRo 1 - OBJETIVOS PRETENDIDOS PELA PROFESSORA

\begin{tabular}{|c|c|}
\hline OBJETIVOS DA PRIMEIRA AULA & OBJETIVOS DA SEGUNDA AULA \\
\hline $\begin{array}{l}\text { 1. Cumprimentos } \\
\text { 2. Praticar o alfabeto } \\
\text { 3. Praticar os números de } 1 \text { a } 10 \\
\text { 4. Soletrar nomes em inglês } \\
\text { 5. Vocabulário: first name, last name, } \\
\text { nickname } \\
\text { 6. Praticar os pronomes his/her }\end{array}$ & $\begin{array}{l}\text { 1. Vamos revisar o alfabeto } \\
\text { 2. Vamos revisar os números de } 1 \text { a } 10 \\
\text { 3. Vocês vão aprender a perguntar o } \\
\text { telefone de alguém e dar a resposta } \\
\text { 4. Vamos ver diferentes formas de } \\
\text { aprender cumprimentar }\end{array}$ \\
\hline
\end{tabular}

Quadro 2 - PercepÇão dos Alunos COM RELAÇão À PRIMEIRA AULA

\begin{tabular}{|c|c|c|c|c|c|c|}
\hline Alunos & Cumprimentos & Alfabeto & NÚMeros & SOletar nOmes & Vocabulário & His/Her \\
\hline A1 & $\mathrm{x}$ & $\mathrm{x}$ & $\mathrm{x}$ & & $\mathrm{x}$ & \\
\hline $\mathrm{A} 2$ & & $\mathrm{x}$ & & & $\mathrm{x}$ & $\mathrm{x}$ \\
\hline $\mathrm{A} 3$ & & $\mathrm{x}$ & $\mathrm{x}$ & $\mathrm{x}$ & & $\mathrm{x}$ \\
\hline
\end{tabular}

Quadro 3 - PercepÇão dos alunos com RelaÇão À SEgunda Aula

\begin{tabular}{|c|c|c|c|c|}
\hline Alunos & Alfabeto & Números & $\begin{array}{c}\text { Perguntar e Responder } \\
\text { (Telefone) }\end{array}$ & Cunprimentar \\
\hline A1 & & $\mathrm{x}$ & $\mathrm{x}$ & \\
\hline $\mathrm{A} 2$ & $\mathrm{x}$ & $\mathrm{x}$ & $\mathrm{x}$ & $\mathrm{x}$ \\
\hline $\mathrm{A} 3$ & & & & $\mathrm{x}$ \\
\hline
\end{tabular}

De modo geral, pode-se dizer que, conforme mostram as pesquisas em sala de aula sobre as intenções de professores e as percepções dos alunos, houve uma lacuna entre os objetivos pretendidos e os mencionados, mesmo em se tratando de aulas de nível elementar, em que as atividades são mais bem definidas, pela própria simplicidade do conteúdo e pela necessidade de torná-lo compreensível. Na primeira aula, aproximadamente $55 \%$ dos objetivos da professora foram mencionados pelos alunos, e, na segunda, 58\%. 
Percebe-se ainda que não houve diferença significativa entre as duas, de modo que não se pode afirmar que a explicitação dos objetivos fez com que a segunda aula apresentasse mais sentido do que a primeira. E se, por um lado, A2 teve uma melhor percepção na segunda aula, quando os objetivos foram explicitados, por outro,a percepção de A3 foi muito pior.

A entrevista com P, ao final da segunda aula, referenda esse resultado, pois $\mathrm{P}$ disse não ter percebido diferença entre as duas aulas. No entanto, ela ressaltou a importância de o professor tomar conhecimento das percepções dos alunos, o que foi feito em três momentos da aula.

Assim, os dados nos permitem afirmar que, em aulas isoladas de nível elementar, a apresentação de objetivos não acarreta uma convergência entre as intenções do professor e as percepções dos alunos, mas a apreciação de alguns dados pode levar o professor a entender melhor como os alunos interpretam os eventos de sala de aula.

\section{DisCUSSÃO}

A análise que faremos a seguir engloba três questões: a percepção dos informantes com relação a atividades menos e mais elaboradas, a relevância das atividades conforme a ênfase com que foram mencionadas e, por fim, a forma como a aprendizagem se mostrou nos dados. As palavras-chave desse continuum são: citação, relevância e aprendizagem.

A única atividade mencionada pelos três alunos foi a segunda da primeira aula, a mais bem definida em termos de foco (a repetição das letras do alfabeto pelos alunos em um círculo). Já nas atividades que conjugavam mais de uma habilidade, o foco dos alunos raramente coincidiu com o da professora. Um exemplo disso foi uma atividade, na segunda aula, em que os alunos tinham de fazer mímica dos números com a cabeça para que os pares os adivinhassem; embora o objetivo da professora fosse a prática dos números, a mímica foi mais relevante, haja vista ter sido mencionada duas vezes por A1 e A2. Um outro exemplo, da primeira aula, foi uma atividade com perguntas What's his/ her name? e respostas His/Her name's ..., cujo objetivo era a prática de his/her, mas foi interpretado, por A1 e A2, como aprendi o nome 
dos colegas, por A2, como memorizar nomes dos colegas, sendo que de his/her A2 disse que havia aprendido a pronúncia.

Quanto mais complexa e elaborada a atividade, mais dificuldades têm os alunos no reconhecimento dos objetivos. No caso da segunda aula, várias atividades foram realizadas para atingir o último objetivo (ver formas diferentes de cumprimentar), como se pode notar na seguinte descrição, retirada das minhas anotações:

1. P perguntou se eles se lembravam de nomes em inglês e escreveu, no quadro, três dos nomes sugeridos: John, Paul e George.

2. P escreveu Lennon após John e perguntou os outros sobrenomes dos componentes dos Beatles. Perguntou ainda se eles gostavam desse grupo.

3. P escreveu yes, stop, bye, white, good e right no quadro e pediu os opostos, que também foram escritos ao lado das palavras correspondentes.

4. P distribuiu a letra da música Hello goodbye, de John Lennon e Paul McCartney, com lacunas para serem preenchidas ao ouvi-la.

5. Ouviu-se a música três vezes e P checou as respostas.

6. Os alunos cantaram a música.

7. P escreveu hello e goodbye no quadro e pediu que os alunos escrevessem, no quadro, expressões usadas ao chegar e sair.

8. P conferiu as respostas e pediu que eles lessem as expressões.

Segundo P, a atividade da música (1 a 6) serviu apenas de introdução para a atividade descrita no item 7 e, como tal, não foi apresentada como objetivo. No entanto, a primeira ocupou muito mais tempo do que a segunda e parece ter sido muito mais relevante, já que os três alunos a mencionaram como um dos objetivos na primeira pergunta da entrevista, e cada um mencionou essa atividade duas vezes no decorrer das outras três perguntas.

Outro elemento dos dados presentes em minhas anotações que ratifica a dificuldade dos alunos em perceber as intenções do professor e que também revela a riqueza da interpretação dos alunos são as respostas dadas a uma pergunta feita por $\mathrm{P}$ para o grupo como um todo, 
em três momentos da segunda aula: "Por que vocês acham que essa atividade foi realizada?”.

A primeira dessas atividades, já mencionada anteriormente, foi feita em pares, quase no início da aula, e cada aluno tinha de fazer mímica de um número com a cabeça para que o outro adivinhasse o número (objetivo: revisar os números de 1 a 10). A pergunta de $\mathrm{P}$ suscitou as seguintes respostas: integração, quebra-gelo, acabar o sono, memorização, despertar curiosidade, facilitar o raciocínio, associar gestos com números em vez de português com inglês e coordenação motora.

A segunda foi outra atividade em pares, em que os alunos perguntaram o número do telefone e obtiveram resposta (What's your phone number? My phone number is ...). Os objetivos nomeados foram: saber o número do telefone do colega, desenvolver a fluência verbal, pensar o que você vai falar, ajudar a quebrar a timidez e forçar a fala e o erro para poder acertar, ao passo que o objetivo de P era "vocês vão aprender a perguntar o telefone de alguém e dar a resposta".

$\mathrm{Na}$ terceira atividade, os alunos tiveram de preencher as lacunas de uma música dos Beatles, após ouvir a fita. Esta atividade visava apenas "introduzir diferentes formas de se cumprimentar"; para os alunos os objetivos foram percebidos como: pronúncia, saber ouvir a fita, ouvir e tentar entender, aprender tudo: ouvir, falar, escrever, memorizar e, por último, aprender a cantar.

É importante salientar que $\mathrm{P}$ sequer tinha um objetivo específico com a música, como já foi dito anteriormente, mas, de modo geral, esses e os outros objetivos citados pelo grupo são bastante aceitáveis e confirmam o caráter idiossincrático das percepções.

Assim, uma das conclusões a que se chega com esse estudo é que atividades comunicativas, que conjugam forma, habilidade e conteúdo diversos e que, além disso, apresentam-se com roupagens diferentes, tais como jogo, música, mímica etc., muito dificilmente podem ser percebidas como possuidoras de apenas um objetivo, ainda que eles sejam explicitados. E, do ponto de vista do professor, a redução de uma atividade caleidoscópica a apenas um objetivo é, no mínimo, uma forma de empobrecê-la. Uma imagem interessante aqui seria a de uma paisagem que o professor quisesse reduzir a um foco apenas, mas que cada aluno tivesse o seu. Várias fotografias dessa paisagem não seriam mais interessantes e significativas para cada um do que apenas uma? 
Uma outra discussão que se apresenta e contribui para aumentar ainda mais a lacuna entre as intenções do professor e as interpretações dos alunos é que quando se diz que os objetivos foram percebidos, mencionados ou citados, isso não significa que eles foram relevantes para os alunos. De fato, muitos deles foram mencionados apenas como itens, à medida que iam surgindo na memória. Assim, parece-nos interessante focalizar os aspectos que pareceram mais relevantes da aula, conforme a ênfase com que foram mencionados.

Vamos nos ater apenas aos dados da segunda aula, já que as respostas foram mais ricas e detalhadas, o que denota sua maior relevância. Os três alunos-informantes destacaram objetivos gerais da abordagem comunicativa, como a prática das habilidades orais, tanto de compreensão quanto de produção, ou estratégias usadas por eles e por P, como se pode notar:

A1: Aprendi a escutar em inglês, a pensar em inglês, a gente está aprendendo a pensar em inglês, pra mim hoje a aula foi destinada a isso. Ela coloca..., eh, até a música que ela colocou pra gente completar, então a gente tem que pensar em inglês (...) Tentava ouvir o que ela falava, pronunciar corretamente e guardar na cabeça realmente números, aqueles gestos, mímica que fez no começo, é, inclusive eu já vou começar a trabalhar com mímica. Acho que todo mundo que começa a trabalhar com mímica, não quer mais falar em português, aí tudo que você vai falar, você gesticula. (...) Pra mim, acho que hoje foi destinado a pensar mesmo em inglês.

A2: Aprendemos a ouvir e a traduzir a música (...) Tentei captar o máximo que eu podia, bom, a mímica da $\mathrm{P}$ ajuda a gente a tá falando inglês na sala, então a gente não tem dificuldade de entender o que ela quer passar pra gente dentro da aula. (...) Tentei falar corretamente as letras do alfabeto... (...) Eu consegui entender a música todinha... (...) acho que a professora ajuda bastante com a mímica dela, já falei, né, ela quase não fala português na sala.

A3: Também treinei muito a minha audição, minha capacidade de captar as palavras em inglês (...) Então, aprendi a ouvir... (...) Cantamos também, e ouvimos bastante inglês. (...) e ouvi inglês bastante o que a professor dizia. 
Block (1996) chegou também à conclusão, ao examinar uma das perguntas que também foi endereçada aos alunos nesse estudo ( $O$ que você aprendeu hoje?), de que os aprendizes tendem a fazer comentários gerais a respeito de como eles melhoraram as habilidades orais de compreensão e produção. No entanto, os resultados da pesquisa de Block divergem desse estudo, quando diz que os informantes fizeram comentários gerais a respeito de terem aprendido vocabulário, sem, contudo, mencionar especificamente o que haviam aprendido.

Vale ressaltar aqui que alguns itens foram citados, demonstrando sua relevância, mas nem por isso indicando que houve aprendizagem, como se pode perceber nesses dois momentos, da primeira e da segunda aula, respectivamente:

\section{Entrevista com A1}

Entrevistador (E): O que você aprendeu hoje?

A1: Eu aprendi a falar três, que eu não sabia falar, aprendi os nomes dos meus colegas, aprendi o que é apelido em inglês.

E: O que é?

A1: Neckname.

\section{Entrevista com A3}

E: A professora o ajudou a realizar essas atividades?

A3: Sem dúvida, ajudou bastante, porque, por exemplo, nas formas de se cumprimentar... eu falava e a professora pedia para que eu fosse até a lousa escrever e, assim, ela apontava onde estava correto ou errado, ou então se o cumprimento estava errado, por exemplo, how do you do... eu queria colocar how do you do e a professora disse que não era conveniente por causa, por ser esta forma de cumprimentar, how do you do é uma forma utilizada quando eu já conheço a pessoa e ela queria que a gente escrevesse... how do you do é para uma coisa coloquial, quando eu tô íntimo da pessoa e não era isso que ela estava propondo, ela estava propondo como se eu tivesse conhecendo a pessoa naquele momento. Seria, por exemplo, how are you? (...) uma das formas ideais, me ajudou bastante a professora, você entendeu o que eu falei? Acho que não deu para entender. 
A confusão de A3 demonstra que mesmo num evento em que, para o aprendiz, a professora é vista como controladora de qualidade termo usado por Richards \& Lockhart (1996) para designar o professor que deve manter a qualidade do uso da língua em sala, reforçando o uso correto e desencorajando o uso incorreto -, pode haver falhas de interpretação.

A discussão desses três pontos que emergiram dos dados objetivos nesse estudo (citação, relevância e aprendizagem) demonstrou que a divergência entre as intenções do professor e as percepções dos alunos foi muito grande e se manifestou tanto em nível superficial, quando os informantes tiveram de apenas mencionar os objetivos, quanto num nível mais profundo, quando eles especificaram o que haviam aprendido. Tal conclusão comprova o que teóricos da área, como Breen (1987), Nunan (1989) e Block (1994) já apontaram, ou seja, os aprendizes de língua não apenas interpretam as atividades de sala de aula, mas também apropriamse delas e fazem delas o que querem.

\section{ConClusão}

Em suma, este estudo se propôs comparar as percepções do professor e dos alunos durante duas aulas, uma em que não houve a explicitação de objetivos, e outra em que os objetivos foram apresentados aos alunos. A análise dos dados nos permite concluir que não houve diferença significativa entre uma aula e outra. Este resultado nos leva à conclusão de que, embora pareça coerente que os objetivos de uma aula devam ser explicitados aos alunos, a simples apresentação deles não implica uma maior convergência entre a intenção do professor e a interpretação do aluno e tampouco garante uma aprendizagem mais bemsucedida, confirmando uma tendência relativamente recente na literatura de aquisição de L2 de que a aprendizagem é resultado de uma interação bastante imprevisível entre aluno, professor e atividades realizadas em sala de aula.

Além disso, uma análise mais detalhada dos dados confirma que as divergências entre as intenções do professor e as percepções dos alunos são várias, não permitindo que professores e produtores de materiais didáticos tenham a palavra final a respeito do que acontece em sala de aula. No entanto, pesquisas longitudinais deveriam ser 
realizadas, no sentido de se comprovarem os efeitos da apresentação de objetivos para o aluno a longo prazo.

É óbvio que este estudo não descarta a importância da apresentação de objetivos como uma maneira de tornar as atividades de uma aula mais coerentes para o aluno; no entanto, o que os dados não nos permitem afirmar é que esta explicitação garanta esta coerência, pois o aluno parece compreender cada atividade de acordo com os próprios conceitos e com uma abordagem pessoal de aprendizagem.

Isto nos leva a crer que mais importante do que a convergência entre as intenções do professor e a interpretação dos alunos é a forma como os alunos percebem as aulas, ou seja, o sentido que eles dão a cada atividade realizada em sala. Talvez uma maior compreensão das maneiras como os aprendizes descrevem e atribuem propósito às atividades pudesse redimensionar a forma como os professores abordam os objetivos. No entanto, de antemão, já se pode adiantar que o ideal seria que os objetivos fossem não apenas ditos, mas negociados, já que uma aula é, na verdade, co-produzida por alunos e professores (AlLwRIGHT \& BAILEY, 1991, p. 25), e os limites que parecem tangíveis em um plano de aula dissolvem-se na cultura que emerge da sala de aula.

\section{Agradecimentos}

À Profa. Laura Miccoli, da Universidade Federal de Minas Gerais, pelos comentários sobre uma versão anterior deste texto; aos quatro informantes que participaram deste estudo.

\section{Abstract}

The evidence, each day more frequent, about the great discrepancy between teacher intention and student perception has led classroom researchers to the conclusion that the pedagogical purpose of a class must be informed to the student. But is it true that the presentation of objectives narrows the gap between teacher intention and student interpretation? This study compares a teacher's and three students' perceptions of the aim of two classes, one in which objectives are stated and another in which they remain unstated.

KeY-Words: Stated and unstated objectives; teacher intention; student perception. 
NOTAS

1. Esta e todas as outras citações presentes neste estudo foram traduzidas por mim.

2. Aqui e no restante desse estudo, os informantes serão mencionados por $P$, A1, A2 e A3.

\section{REFERÊNCIAS}

Allwright, D. \& Bayley, K. M. Focus on the language classroom: an introduction to classroom research for language teachers. Cambridge: CUP, 1991.

BAYley, K. M. The best laid plans: teachers' in-class decisions to depart from their lesson plans. In: Bayley, K. M. \& Nunan, D. (Ed.), Voices from the language classroom. Cambridge: CUP, 1996. p. 15-40.

BLock, D. A day in the life of a class: teacher/learner perceptions of task purpose in conflict. System, v. 22, n. 4, p. 473-486, 1994.

. A window on the classroom: classroom events viewed from different angles. In: Bayley, K. M. \& NunAn, D. (Ed.), Voices from the language classroom. Cambridge: CUP, 1996. p. 168-196.

BREEN, M. Learner contributions to task design. In: Language learning tasks: Lancaster working papers in English language education, v. 7. London: Prentice-Hall, 1987.

Brindley, G.P. Needs analysis and objective setting in the adult migrant education program. Australia: AMES, 1984.

DAkin, J. The language laboratory and language learning. London: Longman, 1973.

Doff, S, A. Teach English. Cambridge: CUP, 1988.

GARDNER, H. Inteligências múltiplas: a teoria na prática. Trad. Maria Carmen Silveira. Porto Alegre: Artes Médicas, 1995.

Kumaravadivelu, B. Language-learning tasks: teacher intention and learner interpretation. ELT Journal, v. 45, n. 2, p. 98-107, 1991. 
Medgyes, P., Malderez, A. Changing perspectives in teaching education. Oxford: Heinemann, 1996.

Nunan, D. The learner-centred curriculum. Cambridge: CUP, 1988. . Hidden agendas: the role of the learner in programme implementation. In: Johnson, R. K. (Ed.), The second language curriculum. Cambridge: CUP, 1989. . Hidden voices: insiders' perspectives on classroom interaction. In: Bayley, K. M. \& Nunan, D. (Ed.), Voices from the language classroom. Cambridge: CUP, 1996, p. 41-56.

Richards, J. C. Beyond training. Cambridge: CUP, 1998.

RichaRDS, J. C. \& Ho, B. Reflective thinking through journal writing. In: Richards, J. C. Beyond training. Cambridge: CUP, 1998. p. 153-170.

Richards, J. C., LockHART, C. Reflective teaching in second language classrooms. Cambridge: CUP, 1996.

WILLIS, J. Teaching English through English. London: Longman, 1981. 